
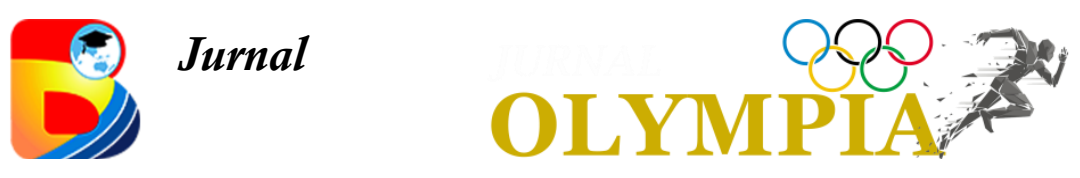

p-ISSN: $2656-5994$

e-ISSN: $2656-5986$

http://journal.binadarma.ac.id/index.php/olympia

\title{
Upaya Meningkatkan Motivasi Siswa Belajar Olahraga Lempar Lembing Dengan Media Lempar Rocket di Sekolah Dasar Negeri 01 Buay Runjung
}

\author{
Erni Cahya Gupita ${ }^{1}$, Antonius Tri Wibowo ${ }^{2}$
}

Universitas Mercu Buana, Yogyakarta, Indonesia ${ }^{1,2}$

\begin{tabular}{l}
\hline Info Artikel \\
\hline Sejarah Artikel: \\
Diterima Desember 2021 \\
Disetujui Februari 2021 \\
Dipublikasikan Maret 2021 \\
\hline Keywords:Motivasi \\
Belajar, Modifikasi \\
Lempar Rocket.
\end{tabular}

\section{Abstrak}

Dalam pembelajaran olahraga atletik kreatifitas guru sangat diperlukan untuk melahirkan ide gerak yang mudah dilakukan oleh siswa, guru dapat memanfaatkan alat-alat sederhana yang terpenting dari semuanya itu adalah faktor kegembiraan pada anak yang ditimbulkan dari kegiatan tersebut, sehingga anak akan tertarik dan mulai menyukai olahraga atletik. Untuk mewujudkan suasana yang menggembirakan diperlukan pengembangan atletik yang bernuansa permainan. Penelitian ini dilakukan untuk meningkatkan motivasi belajar siswa Sekolah Dasar Negeri 01 Buay Runjung terhadap olahraga lempar lembing dengan media lempar rocket. Metode dalam penelitian ini merupakan penelitian tindakan kelas (classroom action research). Adapun jenis data yang digunakan dalam penelitian ini adalah data kualitatif dan data kuantitatif yang terdiri dari data angket (kuesioner) minat belajar siswa. Data hasil evaluasi belajar kognitif, psikomotor, dan afektif pada siswa. Berdasarkan hasil dari angket motivasi dan hasil tes yang diberikan pada saat siklus I nilai rata rata angket motivasi siswa diperoleh 55.80 dan pada siklus II nilai rata rata diperoleh 80.89 sudah terlihat peningkatannya. Sedangkan hasil evaluasi belajar diperoleh rata-rata pada siklus I 66.54 dan pada siklus II diperoleh 81.33 terlihat meningkat dari siklus sebelumnya. Dari hasil perbaikan pembelajaran yang telah dilaksanakan dalam dua siklus, Hasil belajar siswa kelas V Sekolah Dasar Negeri 01 Buay Runjung pada mata pelajaran Penjaskes dengan materi modifikasi lempar lembing menggunakan media rocket mengalami peningkatan yang signifikan setelah pembelajaran menggunakan objek nyata modifikasi lempar rocket dengan metode demonstrasi.

\begin{abstract}
In athletic sports learning Teacher creativity is indispensable to give birth to the idea of motion that is easy to do by students, teachers can make use of simple tools. To realize an exhilarating atmosphere, it is necessary to develop athletic nuanced games. This research was conducted to increase the learning motivation of public Elementary
\end{abstract}


School 01 Buay Runjungto the sport of javelin throwing with rocket throwing media. The method in this study is classroom action research. The types of data used in this study are qualitative data and quantitative data consisting of: Questionnaire data of students' learning interests. Data on cognitive, psychomotor, and affective learning evaluation results in students. Based on the results of the motivation questionnaire and the test results given At the time of cycle I the average value of the student motivation questionnaire obtained 55.80 and in cycle II the average score obtained 80.89 has seen an increase. While the results of the study evaluation obtained average on cycle I 66.54 and In cycle II Obtained 81.33 seen increased from the previous cycle. From the results of the improvement of learning that has been implemented in two cycles, the learning outcomes of grade $V$ students of Elementary School 01 Buay Runjungin penjaskes subjects with javelin throwing modification material using rocket media experienced a significant improvement after learning using real objects modification of rocket throw with demonstration method.

Keywords: learning motivation, rocket throwing modification.

E-mail: ernicahvagupita99@gmail.com ${ }^{1}$ antoniustriwibowo@mercubuana-vogva.ac.id ${ }^{2}$
ISSN 2656-5994(online)

ISSN 2656-5986 (cetak)

\section{PENDAHULUAN}

Pendidikan merupakan suatu proses yang berlangsung panjang dan diorganisasikan dalam lingkungan sekolah dan diluar sekolah menurut pola pola tertentu yang dianggap baik. Pada umumnya para pendidik berpendapat bahwa tugas lembaga pendidikan mendorong pertumbuhan seseorang dengan tujuan yang diharapkan oleh individu dan masyarakat sekitarnya dapat tercapai (Rusli Lutan dan Adang Suherman, 2000:8).

Proses pembelajaran pendidikan jasmani semestinya guru mengajarkan berbagai gerak dasar, teknik dan strategi pembelajaran menanamkan nilai nilai nilai (sportifitas, kejujuran, kerjasama, dan lain-lain) dari pembiasaan pola hidup sehat. Aktivitas yang diberikan dalam pengajaran harus mendapatkan sentuhan dikdaktik-metodik, sehingga aktivitas yang dilakukan dapat mencapai tujuan pengajaran yang diinginkan. Di dalam pendidikan, seorang guru perlu melakukan inovasi dan memanfaatkan metode ataupun pengembangan metode pembelajaran yang inovatif dan tentunya melihat lingkungan tempat guru mengajar (Wibowo \& Kushartanti, 2013). Di dalam pelaksanaan pembelajaran atletik, seorang guru penjaskes dapat memanfaatkan alat-alat yang sederhana.

Olahraga atletik merupakan gabungan dari beberapa jenis olahraga yang secara garis besar dapat dikelompokan menjadi aktivitas lari, lempar, dan lompat (termasuk tolak) merupakan pola gerak dasar yang mewarnai sebagian besar cabang olahraga. Ketiga pola 10 
gerak dasar tersebut berasal dari cabang olahraga atletik (Qomarullah, 2012). Lempar merupakan salah satu nomor yang terdapat dalam cabang olahraga atletik yang diperlombakan baik dalam olahraga yang bersifat nasional dan internasional. Menurut Munasifah, (2008) lempar lembing terdiri dari dua kata yaitu lempar dan lembing. Lempar bermakna usaha untuk membuang jauh-jauh, dan lembing bermakna tongkat yang berujung runcing. Jadi lempar lembing bermakna togkat berujung runcing yang dibuang jauh-jauh. Mengenai sejarah kapan dimulainya olahraga lempar lembing, sampai saat ini masih belum jelas informasinya.

Dalam pembelajaran olahraga atletik Kreatifitas guru sangat diperlukan untuk melahirkan ide gerak yang mudah dilakukan oleh siswa, guru dapat memanfaatkan alat alat yang sederhana dan terpenting dari semuanya itu adalah faktor kegembiraan pada anak yang ditimbulkan dari kegiatan tersebut, sehingga anak tertarik dan mulai menyukai olahraga atletik. Untuk mewujudkan suasana yang menggembirakan diperlukan pengembangan atletik yang bernuansa permainan. Guru harus mampu mengemas kegiatan disajikan dalam bentuk tugas-tugas gerak yang mudah dimengerti anak sesuai dengan keadaan jiwanya dalm proses pembelajaran. (Yudha M. Saputra, 2001:5).

Menurut yoyo bahagia dkk. (2000:34), konsep modifikasi permainan dan olahraga pada dasarnya memiliki kesamaan dengan konsep pengembangan pentahapan belajarnya. Modifikasi pembelajaran permainan dapat disederhanakan melalui pengurangan dan penambahan struktur permainan itu sendiri tanpa mengurangi hakekat dan tujuan dari pendidikan jasmani. Struktur-struktur tersebut diantaranya: (1) ukuran lapangan, (2) bentuk, ukuran dan jumlah peralatan yang digunakan, (4) jenis skill yang digunakan, (5) aturan, (6) jumlah pemain, (7) organisasi permainan dan (8) tujuan permainan.

Adanya modifikasi permaianan atau pembelajaran diharapkan Agar standar kompetensi pembelajaran pendidikan jasmani dapat terlaksana sesuai dengan program, maksud dan juga tujuan sebagaimana yang ada dalam kurikulum, maka guru pendidikan jasmani harus mampu membuat pembelajaran yang efektif dan menyenangkan. Untuk itu perlu adanya pendekatan, variasi maupun modifikasi dalam pembelajaran atletik pada nomor lempar yang menyeluruh dengan modifikasi pembelajaran lempar lembing.

Hasil studi literatur penelitian relevan yang peneliti lakukan mendapatkan fakta bahwa:

1) Jenjang pendidikan anak usia dini pengembangan aktivitas fisik terprogram sudah diberikan melalui permainan sirkuit (Taroreh, 2017).

2) Secara khusus sudah dikembangkan juga program aktivitas fisik manipulatif berbasis kinestetik untuk anak usia 6 tahun (Taroreh \& Wijaya, 2020).

3) Permainan tradisional dapat dikembangkan sebagai materi pembelajaran atletik di Sekolah Dasar (Musiandi \& Taroreh, 2020). 
4) Permainan CBA (Culture Based Athletic) pada pembelajaran atletik sebagai solusi alternatif melestarikan perrmainan tradisional di Sumatera Selatan (Taroreh \& Satria, 2020).

5) Pengembangan dilakukan tidak hanya pada materi pembelajaran namu juga pada instrument penilaian sebagai contoh model penilaian kinerja hasil pembelajaran permainan bola voli di Sekolah Dasar (Taroreh, 2012)

6) Pada jenjang Sekolah Menengah Pertama (SMP) model pengembangan pembelajaran lari jarak pendek efektif dalam pembelajaran pendidikan jasmani terutama pada materi model pembelajaran lari jarak pendek pada siswa Sekolah Menengah Pertama dengan nilai rata-rata sebelum tes 57.85 dan rata-rata sesudah tes 63.85 (Mayanto dkk., 2021).

7) Pada jenjang Sekolah Menengah Atas (SMA) pengembangan pembelajaran lari melalui media Flash Card di Sekolah Menengah Atas juga sudah diterapkan (Nahar \& Taroreh, 2020).

Hasil observasi di Sekolah Dasar Negeri 01 Buay Runjung peneliti memfokuskan tiga masalah yaitu 1) alat lembing yang asli cukup beresiko dan berbahaya bagi keselamatan peserta didik, modifikasi alat yang dilakukan guru penjaskes masih belum dilakukan dengan demikian siswa kesulitan dalam melakukan lemparan, 2) kurangnya motivasi belajar peserta didik sehingga hilangnya fokus siswa dengan materi yang diberikan sehingga peserta didik kurang mampu memahami materi, 3) tidak adanya alat peraga sebagai pengganti lembing yang asli sebagai sarana yang dimiliki oleh pihak sekolah untuk mengenalkan olahraga lempar lembing kepada siswa.

Dari uraian di atas lempar rocket digunakan sebagai media pendekatan dalam upaya meningkatkan motivasi belajar lempar lembing pada siswa. Peningkatan dalam belajar lempar lembing, adalah mengenai: peningkatan kesungguhan siswa dalam mengikuti proses pembelajaran (peningkatan minat, motivasi, dan partisipasi siswa dalam proses pembelajaran) serta peningkatan hasil belajar siswa melalui unjuk kerja siswa dalam melakukan tes lempar lembing.

\section{METODOLOGI PENELITIAN}

Metode dalam penelitian ini merupakan penelitian tindakan kelas (PTK) atau istilah yang sering disebut dalam bahasa inggris sebagai (classroom action research). Penelitian tindakan kelas merupakan penelitian praktis yang dimaksudkan untuk memperbaiki pembelajaran di kelas Menurut Wijaya Kusuma (2009:9) penelitian tindakan kelas adalah penelitian tindakan yang dilakukan oleh guru di dalam kelas. PTK dapat diartikan sebagai proses pengkajian masalah pembelajaran di dalam kelas melalui refleksi diri dalam upaya untuk memecahkan masalah tersebut dengan melakukan berbagai tindakan yang terencana dalam situasi nyata serta menganalisis setiap pengaruh dari perlakuan tersebut. Metode yang digunakan adalah deskriptif kuantitatif. Masyhuri 
(2008:34) menjelaskan bahwa penelitian yang bersifat deskriptif merupakan penelitian yang memberi gambaran secermat mungkin mengenai suatu individu, keadaan, gejala atau kelompok tertentu. Metode penelitian kuantitatif yang dijelaskan oleh sugiyono (2011:14) metode penelitian sebagai metode yang berlandaskan pada filsafat positivisme: metode yang digunakan untuk meneliti pada populasi atau sampel tertentu; teknik pengambilan sampel biasanya dilakukan dengan perhitungan teknik sampel tertentu yang sesuai; pengumpulan data kuantitatif/statistik dengan tujuan untuk menguji hipotesis yang telah ditetapkan.

Populasi dan sampel dari penelitian tindakan kelas ini adalah peserta siswa kelas V Sekolah Dasar Negeri 01 Buay Runjungdi Desa Belambangan Kabupaten Oku Selatan dengan jumlah siswa 28 anak terdiri dari 15 siswa putra dan 13 siswi.

Setiap penelitian harus direncanakan untuk itu diperlukan suatu desain penelitian. Desain penelitian merupakan rencana tentang melaksanakan penelitian. Menurut Nasution (2003:23) dijelaskan bahwa "desain penelitian merupakan rencana tentang mengumpulkan dan menganalisis data agar dapat dilaksanakan ekonomis serta serasi dengan tujuan penelitian itu. Desain penelitian merupakan suatu bentuk strategi untuk mencapai sebuah tujuan penelitian yang sudah ditetapkan dan berperan sebagai tuntutan atau pedoman yang dilakukan pada seluruh proses penelitian.
Penelitian tindakan ini dilaksanakan dalam 2 siklus, yang terdiri dari 4 setiap tahapannya yaitu planning (perencanaan), action (tindakan), observation (pengamatan), reflection (refleksi).

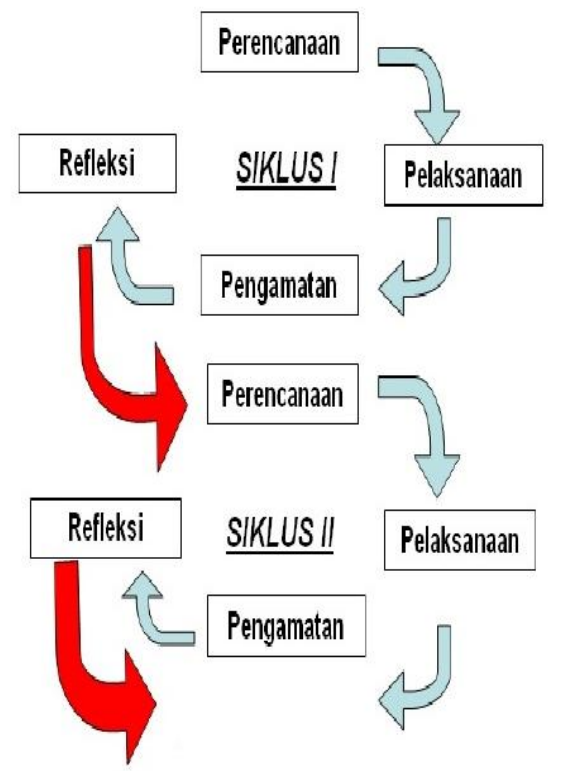

Gambar 1. Alur Pelaksanaan Penelitian Tindakan Kelas

Jenis data yang digunakan dalam penelitian ini adalah data kualitatif dan data kuantitatif yang terdiri dari data angket (kuesioner) minat belajar siswa. Data hasil evaluasi belajar kognitif, psikomotor, dan afektif pada siswa. Untuk mengetahui suatu keefektipan suatu metode dalam kegiatan pembelajaran perlu dilakukan analisis data Penelitian ini menggunakan metode deskriptif kuantitatif dengan membandingkan hasil belajar siswa sebelum tindakan dengan hasil belajar siswa pada tiap siklus.

Data tentang peningkatan motivasi dan tanggapan siswa dalam menggunakan pembelajaran modifikasi olahraga lempar lembing dengan media rocket diambil dengan angket atau kuesioner. Untuk mengetahui 
persentase siswa dari data angket yang diperoleh dengan menggunakan rumus sebagai berikut:

$$
P=\frac{\sum \text { skor perolehan }}{\sum \text { skor total }} \times 100 \%
$$

Keterangan :

$\mathrm{P}=$ tingkat keberhasilan

Adapun kriteria motivasi siswa adalah sebagai berikut:

$81,25-100$ : Minat siswa sangat tinggi

$62,49-81,24$ : Minat siswa tinggi

42,73-62, 48 : Minat siswa cukup tinggi

\section{$25-43,72$ : Minat siswa kurang tinggi}

Analisis data kuantitatif didapat dari penilain pembelajaran berasal dari nilai tes (pretest dan postest). Penilain pembelajaran dan tes mencari nilai rata-rata. Peneliti menjumlahkan nilai yang diperoleh siswa, kemudian dibagi dengan jumlah siswa yang mengikuti tes sehingga diperoleh nilai ratarata dengan rumus:

$$
x=\frac{\sum x}{\sum N}
$$

Keterangan :

$$
\begin{aligned}
& \mathrm{x}=\text { nilai rata }- \text { rata } \\
& \Sigma \mathrm{x}=\text { jumlah semua nilai siswa } \\
& \Sigma \mathrm{N}=\text { jumlah siswa yang mengikuti }
\end{aligned}
$$

Penilaian untuk ketuntasan belajar menghitung ketuntasan belajar secara klasikal yaitu mengukur tingkat keberhasilan ketuntasan belajar siswa secara meyeluruh. Untuk menghitung presentasee ketuntasan klasikal menggunakan rumus:

$$
P=\frac{\Sigma \text { jumlah siswa yang mendapat nilai } \geq 65 \times 100 \%}{\Sigma \text { siswa mengikuti tes }}
$$

Ketuntasan belajar klasikal dikatakan berhasil apabila jika presentase siswa yang tuntas belajar/siswa yang mencapai nilai $\geq 65$ jumlahnya lebih besar atau sama dengan presentase $85 \%$ dari jumlah siswa seluruhnya.

\section{HASIL DAN PEMBAHASAN}

Berdasarkan hasil pengamatan dan evaluasi yang dilakukan mengenai kondisi awal pembelajaran olahraga lempar lembing dengan menggunakan media lempar rocket kelas V di Sekolah Dasar Negeri 1 Buay Runjung belambangan menunjukkan 1) kurangnya minat siswa dalam mengikuti pembelajaran, 2) siswa sangat pasif dalam kegiatan pembelajaran, 3) siswa kurang aktif dalam menjawab pertanyaan dan mempraktikkan apa yang di perintahkan guru, 4) dari hasil pengamatan terhadap lembar jawaban siswa terlihat kurang kemampuan siswa dalam penyelesaian soal sehingga hasil belajar siswa rendah diperoleh bahwa minat dan hasil belajar siswa mengalami peningkatan dari siklus ke siklus. Berdasarkan pelaksanaan evaluasi pembelajaran dapat dilihat dari hasil nilai evaluasi kelas V Sekolah Dasar Negeri 01 Buay Runjung belambangan dari siklus I dan siklus II.

Peningkatan nilai rata rata hasil angket motivasi siswa dan evaluasi belajar siswa kelas V Sekolah Dasar Negeri 01 Buay Runjung dapat dilihat pada grafik berikut: 


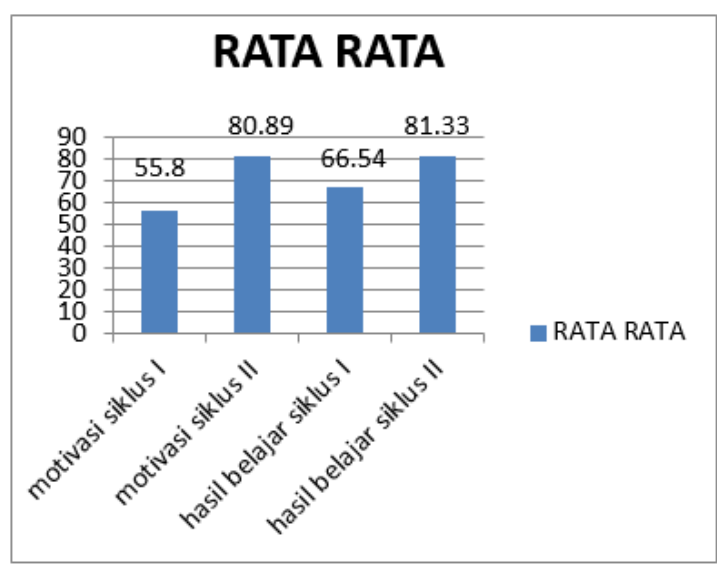

Gambar 2. Nilai Rata-Rata Angket Motivasi dan Hasil Belajar Siswa Selama Perbaikan Pembelajaran

Berdasarkan hasil dari angket motivasi dan hasil tes yang diberikan pada saat siklus I nilai rata rata angket motivasi siswa diperoleh 55,80 dan pada siklus II nilai rata rata diperoleh 80,89 sudah terlihat peningkatannya. Sedangkan hasil evaluasi belajar diperoleh rata rata pada siklus I 66,54 dan pada siklus II diperoleh 81,33 terlihat meningkat dari siklus sebelumnya, dari 28 siswa hasil minat angket motivasi siswa mulai dari siklus I persentase minat siswa sangat tinggi $0 \%$, persentase minat siswa tinggi $32 \%$, persentase minat siswa cukup tinggi $61 \%$, persentase minat siswa kurang 7\%. Pada hasil angket motivasi siswa siklus II persentase 68\% minat siswa sangat tinggi berjumlah 19 siswa, persentase minat siswa tinggi $32 \%$ berjumlah 9 siswa, persentasi minat siswa cukup tinggi $0 \%$, presentasi minat siswa kurang tinggi 0\%. Berdasarkan hasil evaluasi belajar siswa pada ketercapaian ketuntasan siklus I yaitu 13 siswa atau $46 \%$ mencapai KKM, 15 siswa 59\% sedangkan pada siklus II nilai yang mencapai KKM 65 yaitu 25 siswa atau $89 \%$.

Hasil perolehan nilai rata rata yang diperoleh siswa pada perbaikan pembelajaran dari siklus ke siklus mengalami peningkatan. Berdasarkan hasil analisis data, pada siklus II terjadi peningkatan nilai rata rata dibandingkan dengan siklus I. Pada siklus I persentase kenaikan siswa masih belum memuaskan pada motivasi siswa hanya cukup tinggi $61 \%$, persentase minat siswa kurang 7\%. Untuk hasil ketuntasan siklus I yaitu 13 siswa atau $46 \%$ dari 28 siswa. Pada proses perbaikan pembelajaran siklus II diperoleh hasil yang lebih menggembirakan dibandingkan dengan siklus I, yaitu hasil minat siswa $68 \%$ minat siswa sangat tinggi berjumlah 19 siswa, persentase minat siswa tinggi 32\% berjumlah 9 siswa. Untuk hasil belajar yang mencapai KKM 65 yaitu 25 siswa atau $89 \%$.

Dari data di atas dapat disimpulkan, bahwa tindakan yang diberikan pada siklus II telah mencapai hasil yang baik. Dengan demikian penelitian tindakan kelas pada siklus II Sudah dianggak cukup, karena hampir semua siswa dikelas $\mathrm{V}$ hampir mencapai kriteria ketuntasan minimal.

\section{KESIMPULAN}

Dari hasil perbaikan pembelajaran yang telah dilaksanakan dalam dua siklus, hasil belajar siswa kelas V Sekolah Dasar Negeri 01 Buay Runjung pada mata pelajaran Penjaskes dengan materi lempar lembing menggunakan media rocket mengalami 
peningkatan yang signifikan setelah pembelajaran menggunakan objek nyata modifikasi lempar rocket dengan metode demonstrasi. Pada hasil angket motivasi siswa dan hasil evaluasi belajar siswa proses pembelajaran telah diuraikan di depan maka hasil penelitian dapat ditarik kesimpulan bahwa melalui modifikasi media lempar rocket dapat meningkatkan motivasi belajar lempar lembing pada siswa Sekolah Dasar Negeri 01 Buay Runjung dan meningkatkan hasil belajar seta keaktifan para siswa dalam pembelajaran lempar lembing.

\section{DAFTAR PUSTAKA}

Agus Susworo, D. M., \& Saryono. (2009). Tes Keterampilan Dasar Bermain Futsal. Jurnal IPTEK Olahraga.

Adang Suherman. (2000). Dasar-dasar Penjaskes. Jakarta: Depdiknas.

Akis Mayanto, Muhamad Syamsul Taufik, Adi Wijayanto, Soleh Solahuddin, \& Bangkit Seandi Taroreh. (2021). Model Pembelajaraan Jarak Pendek Pada Siswa Sekolah Menengah Pertama. Jurnal Kejaora (Kesehatan Jasmani Dan Olah Raga), 6(1), 114-120. https://doi.org/10.36526/kejaora.v6i1.11 $\underline{74}$.

Bahagia, Yoyok \& Suherman, Adang. (2000). Prinsip-Prinsip Pengembangan dan Modifikasi Cabang Olahraga. Jakarta: Depdikbud Dirjen Pendidikan Dasar dan Menengah.

Kusumah, Wijaya \& Dwitagama, Dedi. (2011). Penelitian Tindakan Kelas. Jakarta: PT Indeks.

Masyhuri, \& Zainuddin, M. (2008). Metodologi Penelitian Sosial dan Ekonomi, Teori dan Aplikasi. Alfabeta: Bandung.
Munasifah. (2008). Atletik Cabang Lempar. Semarang: Aneka Ilmu.

Musiandi, T., \& Taroreh, B. S. (2020). Pengembangan Pembelajaran Atletik Melalui Pendekatan Permainan Tradisional Sumatera Selatan. Jurnal Olympia, 2(1), 29-37. https://doi.org/10.33557/jurnalolympia.v $2 \mathrm{i} 1.885$.

Nahar, A., \& Taroreh, B. (2020). Pengembangan Model Pembelajaran Lari Melalui Media Flash Card di Sekolah Menengah Atas. Jurnal Olympia, 2(2), 34-41. Retrieved from http://journal.binadarma.ac.id/index.php/ olympia/article/view/1266.

Nasution. (2003). Metode Penelitian Naturalistik Kualitatif. Bandung: Tarsito.

Sugiyono. (2011). Metode Penelitian Kuantitatif, Kualitatif dan $R \& D$. Bandung: Afabeta.

Taroreh, B. S. (2012). Model Performance Assesment of Learning Outcomes of Volleyhool Ball in Elementary School. Journal of Physical Education and Sports, $\quad$ l(2), 79-86. https://doi.org/10.15294/JPES.V1I2.80.

Taroreh, B. S. (2017). Development Model Approach Through Exercise Kinesthetic Game Circuit for Children Ages 4-6 Years. JIPES - Journal of Indonesian Physical Education and Sport, 3(1), 41. https://doi.org/10.21009/JIPES.031.06.

Taroreh, B. S., \& Satria, M. H. (2020). Implementasi Permainan CBA pada Pembelajaran Atletik sebagai Solusi Alternatif Melestarikan Permainan Tradisional di Sumatera Selatan. Jurnal Curere, $4(1)$. https://doi.org/10.36764/jc.v4i1.348.

Taroreh, B. S., \& Wijaya, M. A. (2020). Program Aktivitas Fisik Manipulatif Berbasis Kinestetik Untuk Anak Usia 6 Tahun. Jurnal Penjakora, 7(1), 1-10. https://doi.org/10.23887/penjakora.v7i1 
Qomarullah, R. (2012). Metode Pembelajaran Atletik Dasar. Kudus: Maseifa Jendela Ilmu.

Wibowo, A., \& Kushartanti, W. (2013). Modifikasi Permainan Sepakbola bagi Siswa SMA Penderita Asma. Jurnal Keolahragaan, 1(2), 104-119. https://journal.uny.ac.id/index.php/jolahr aga/article/view/2567/2121.

Yudha, M. Saputra. (2001). Pembelajaran Atletik Di Sekolah Dasar (Sebuah Pendekatan Pembinaan Gerak Melalui Permainan). Jakarata: Depdiknas. 